\title{
Communications Apprehension: A Note About Ethnic Diversity
}

\section{IBRAHIM M. ALY \& MAUREEN P. STERLING GOWING ${ }^{*}$}

Concordia University

\section{ABSTRACT}

This paper summarizes the results of an intercultural survey of an ethnically diverse group of students in a Canadian university commerce program. The sample self-reported the level of communications apprehension on the 24-item Personal Report of Communication Apprehension, which uses six questions in four communications settings to generate four subscores and one general score for communications apprehension (McCroskey, 1982). While prior research results showed that the level of communications apprehension varies among ethnic groups, our research results showed no significant variation.

\section{RÉSUMÉ}

Cet article récapitule les résultats d'une enquête interculturelle faite auprès d'un groupe d'étudiants, hétérogène au plan ethnique, issu d'un programme universitaire en administration. Les répondants ont évalué leur degré d'appréhension de communication à partir du questionnaire Personal Report of Communication Apprehension (McCroskey, 1982). Cet instrument, composé de 24 énoncés, mesure l'appréhension de

* The authors gratefully acknowledge the constructive comments provided by the editor and two anonymous reviewers of this study. 
communication via six énoncés reliés à quatre structures de communication. Bien que les recherches antérieures aient démontré que le degré d'appréhension de communication varie selon le groupe ethnique, nos résultats ne supportent pas cette hypothèse.

\section{INTRODUCTION}

One of the most common and often reported fears is that of public speaking. Daly and McCroskey (1974) labeled this phenomenon communications apprehension (CA). CA has been defined as the level of fear associated with either real or anticipated communication (McCroskey, 1977, 1978). The current literature points to two types of CA: trait and context-based. The trait approach assumes that once a person has developed a level of communications apprehension, it becomes an enduring personality trait, also referred to in the literature as shyness and observed behaviorally as reticence (McCroskey, 1984). This approach views communication apprehension as a personality-type orientation toward communication across a variety of contexts or in a given context, such as speaking in meetings (McCroskey, 1984). CA is a learned condition that has its beginning early in a person's life and arises as a result of unpleasant experiences while interacting with others (Friedrich \& Gross, 1984). Our study adopted the situational or context-based approach, which investigates variation in the level of communications apprehension that will be expressed, depending on the context the respondent has been asked to anticipate.

McCroskey (1984) has developed a 24-item instrument that measures CA. The Personal Report of Communication Apprehension (PRCA) elicits an individual's personal feelings about communicating in public, and includes six items in each of four communication settings: public speaking, talking in meetings, talking in group discussions, and talking with another person. It uses a five-step Likert scale, and allows a researcher to calculate five CA scores for any person, one for each of the four communication settings and one overall score.

The PRCA has been administered to over 25,000 college students in the U.S., most of whom have been enrolled in communications courses. 
The overall PRCA score may range from 24 (minimum CA) to 120 (maximum CA). The scores have been shown to form a normal distribution with a mean of 65.6 and standard deviation of 15.3 (McCroskey, 1984). The instrument has internal reliability of approximately 0.94 and has shown considerable evidence of validity (McCroskey, 1977, 1978, 1984).

In comparison, the sample for this study was drawn from those students enrolled in a commerce program at a Canadian university. It should be noted that for over a quarter of a century, the province in which this study was conducted has vigorously attempted to establish a robust alternative cultural context to resist identification with and assimilation into the Anglo-U.S. culture. Unlike the U.S., Canada acknowledges two separate but equal founding cultures identifiable by language, one French and the other English. A formal policy of bilingualism and an ongoing debate about what constitutes the national entity of Canada differentiates the political climate from that of the U.S. The metaphor often used to describe the U.S. is the melting pot, while Canadians have chosen instead the metaphor of the cultural mosaic. The cultural norm of diversity is actively supported in the educational system although support for diversity programs is often inadequate.

The predominantly French-speaking province of Quebec was the site for this study. It could be argued that because the language of instruction remains English, the university in which the study was conducted represents a linguistic, if not an ethnic, minority itself. One notable success at the university has been the implementation of its formal policy to encourage a broad cultural diversity within both its teacher and student populations. International students, landed immigrants, and those who only recently obtained Canadian citizenship comprise a substantial proportion of students enrolled in the commerce program. The study of communications apprehension was undertaken to assess any evidence of systemic barriers to academic and career success based on ethnic origin that might be present in some teaching methods.

Communications apprehension describes the fear people feel as they either anticipate or engage in oral communication with at least one other person (Stanga \& Ladd, 1990). High levels of communication apprehension affect both the way instructors award marks, and the opportunities 
for entry into and success in a profession. Studies of students, undertaken since the early 1970 s, repeatedly confirm that what has also been called stage fright can have both direct and indirect impact on a student's academic and professional success. Although McCroskey and Andersen (1976) pointed out that in academic environments where a lecture-format curtailed the opportunity for the students to communicate either directly with the instructor or to larger groups, there was no difference in academic achievement between students with high and low communications apprehension. McCroskey (1977) measured the influence of high communications apprehension on the student's grade point average and reported a difference of one-half a grade point on a 4-point scale, between students with high and low communications apprehension.

We surveyed 334 university students enrolled in a commerce program, using the Personal Report on Communications Apprehension (PRCA) to assess whether or not ethnic origin affected the reported levels of CA within the sample. The survey addresses CA in four different contexts, dyadic, small groups, classrooms or meetings, and public speaking (McCroskey, 1982). The reliability of this survey instrument exceeds 0.90 and there is substantial evidence of the instrument's predictive validity (McCroskey, 1984).

Whereas the causes of trait-based CA have been explained using cognitive theories, context-based CA is believed to be directly and highly correlated to: attributes of the situation, for example novelty, formality, and unfamiliarity with the audience; and to attributes of the speaker, for example, conspicuousness. The correlates of CA are, however, more complex. Prior research has revealed an inverse correlation between the level of CA, the level of audience attentiveness, and the speaker's previous experience of failure or success. Moreover, CA escalates with a lack of communications skills (Blatzer, 1997). Our empirical study was motivated by the implications of recent communications competence theory, namely that students whose ethnic origin is not AngloU.S. are more likely to be unfamiliar with the expectations of an Anglo-U.S. audience, and less confident with their oral communications skills. We anticipated that students of non-Anglo-U.S. origins would report a higher level of CA than normal. This was not the case. 
CA has both social and practical implications. CA affects academic performance, dropout rates, employment opportunity in the accounting profession, and subsequent career success. Studies of the link between the level of CA and educational attainment have shown first, people who are otherwise competent, but whose CA is higher than the norm are more likely to drop out of four-year college programs (McCroskey, BoothButterfield, \& Payne, 1989). Second, compared to students who reported low levels of CA, those who reported higher than average levels of CA obtained lower grade point averages (GPA). On average these students obtained GPAs one half-point lower on a 4-point scale compared to those with low levels of CA (McCroskey, 1977; McCroskey \& Andersen, 1976). Preliminary studies by Klopf and Cambra (1979) reveal systematic differences in levels of CA that vary with ethnic origin.

It was Akerlof (1970) who used higher education as an example of a widely used guarantee of skills and accomplishment, which ethnic minority groups acquired to improve their access to professions. The results of CA studies imply that people with sufficient technical skill and intellect to succeed in advanced education but who are of diverse ethnic backgrounds, have a higher level of CA and are more likely to drop out before obtaining the very guarantee that will provide them with equal opportunity to. enter the professions. Moreover those with high CA, who remain enrolled, are likely to obtain lower GPAs. A strong correlation between ethnic origin and a high level of $\mathrm{CA}$ would provide a reasonable basis to infer that CA is a systematic barrier to advanced education. One could conclude that advanced, formal education, which should provide one means to equalize opportunity to enter, for example, the accounting profession cannot achieve that goal without remedying systematic differences in CA.

For firms in the accounting profession, the GPA is one of the two primary determinants of an employment candidate's desirability, and the candidate's success at the initial employment interview will depend on their communications skill (Kryzystofik \& Fein, 1998). Those of diverse ethnic origin, however, have less confidence in their skill and therefore higher CA (Blatzer, 1997). The importance of effective communication also shadows the career of a professional accountant because of the extensive telephone and face-to-face work with clients. As accountants 
advance in their careers, so too does the importance of effective interpersonal communication in a variety of professional and social situations (McThomas \& Hanson, 1987). One mitigating factor is that people with high CA also have lower career aspirations. Unfortunately their professional tenure is also $50 \%$ shorter than those with low communication apprehension (Scott, McCroskey, \& Sheahan, 1978). Thus, for students who want to enter the accounting profession, a high level of CA can be a barrier to obtaining a degree, obtaining sufficiently high marks, obtaining employment interviews, obtaining employment offers, obtaining promotions, and retaining their jobs.

The issue of justice and equality of opportunity, as well as practical issues of attracting and retaining skilled, intellectually talented students in accounting programs, are particularly acute in an ethnically diverse student population. If the courses are designed in ways that systematically exclude one group or another from success, irrespective of ability, then the method of accounting education poses a significant social problem. Another consideration is that of the pedagogical appropriateness of oral presentations (Bonner, 1999). One obvious answer to the problem of communications would be to simply provide many opportunities for students to practice their public speaking skills. However, as Bonner, 1999 pointed out, oral presentation by students is appropriate when the pedagogical objective is that students learn either how to synthesize higher order rules into a new rule, or how to develop cognitive strategies for problem-solving. A second obvious answer is to offer lecture-format courses to large groups of accounting students and thereby sidestep the issue of different levels of CA. Indeed, McCroskey and Andersen (1976) found no differences in academic achievement in this sort of educational environment, despite differences in levels of CA. In so doing, however, the method of accounting education would pose a significant practical problem for the profession. Students who already misperceive the accounting profession as one requiring little interpersonal communication receive no "reality check" during their educational process, and are improperly equipped to succeed in the profession (Daly \& McCroskey, 1974). The research results explore the possibility that there may be a 
conflict between achieving pedagogical objectives and achieving practical skills to succeed in the accounting profession.

Our empirical study of differences in levels of CA among students who were either of Anglo-U.S. or non-Anglo-U.S. ethnic background was done to reveal the existence and extent of any systematic difference. The admissions policy of the university where students were surveyed encourages a flourishing, ethnically diverse, and successful student population. The formal mission of the university is to adequately prepare its students for employment and a successful career. The purpose of the survey was to gather information about the correlation of ethnic origin and level CA to determine what empirical differences if any exist within the student sample.

Empirical studies of CA include both cross-cultural and intercultural studies. Cross-cultural studies compare and rank self-reported CA for people who anticipate communicating with each other within a culture (Klopf, 1984). Intercultural studies, however, examine self-reported CA for people from different cultures who anticipate an interaction with one another (Koester, Wiseman, \& Sanders, 1993). This is an empirical study of intercultural CA. Based on existing theories in communications competence, crosscultural communication, and communications apprehension, the outcomes of the study derive some practical results that can be applied when considering changes to existing accounting programs. These questions include: is the level of CA in ethnically diverse populations most appropriately addressed in accounting education programs; in whose interests is it for universities to devote resources to programs to reduce $C A$; how can the $C A$ needs of people of diverse ethnic origin be best identified; what sort of program would best assist them in achieving lower levels of CA; what sort of programs would best assist instructors in assessing the competence of students from ethnically diverse origins; and how to simultaneously achieve reduced CA and pedagogical objectives?

\section{THEORY}

Lines of research in communications competence, intercultural communications, and communications anxiety converge in this study. This section summarizes recent relevant literature in each area of intercultural 
communications anxiety. Communications competence has been developed in primarily in the Anglo-U.S., middle class, college-educated, white communities. This sample does not seem to pose a problem of generalizability for our study because it was undertaken in a sample largely homogeneous with those used in prior research. Communications apprehension affects communications competence, which is now understood as largely a relational concept that depends upon not only the speaker, the goal, and the situation, but also on the audience. The onus, however, is on the speaker to meet the expectations of the audience by speaking in both an appropriate and effective manner. Effectiveness achieves the goal of minimizing misunderstanding (Gundykunst, 1993). The audience's expectations depend on the cultural context, the type of task, the degree of intimacy, and the function or reason for the interaction. To the extent that the speaker can anticipate meeting the audience's expectations and minimizing misunderstanding, the speaker can reduce communications apprehension.

Of particular interest in this study is the notion that cultural context arises from the national, ethnic, and racial origins of the audience (Martin, 1993). The implication is that if the speaker is not of the same ethnic origin as those in the audience who will assess the speaker's competence, the behavior exhibited is less likely to conform to the audience's understanding of what is both appropriate and effective. As Martin (1993) observed, the difference in ethnic origin affects how the speaker exhibits traits such as self-esteem, assertiveness, expressiveness, friendliness, politeness, appropriate role and so on. These traits are consistent in that they are meso rather than macro or micro dimensions of what a speaker needs to exhibit in order to meet the audience's expectations of communications competence. Comparative studies have confirmed that while there is considerable stability in the expectations of an audience across cultures, the relative importance of these expectations and specific behaviors considered appropriate to exhibit competence show considerable variation (Martin, 1993). The implication for our research is that the less familiar the speaker is with the cultural context of the audience, the higher will be the CA. In Figure 1, on page 220, ethnic origin and communications effectiveness are illustrated as characteristics of the speaker. 
Gundykunst (1993) noted that intercultural communication is a novel experience and that novelty causes both a cognitive effect, uncertainty about what is expected or appropriate, and an affective effect, anxiety or apprehension about whether the outcome will be satisfactory. The idea of novelty differs from that of familiarity in that one can be quite familiar with the cultural context of an audience even if it is one's first experience speaking in public. By comparison, communications apprehension research suggests that while the reduction of anxiety is related to reduced novelty, it is also related to successful prior experience. That is, unsuccessful prior experience will reduce novelty but not anxiety. In contrast to the communications apprehension literature, however, Gundykunst (1993) describes not correlational but rather forty-nine causal relationships among different variables with both uncertainty and anxiety.

Of interest among these are some of the direct causal relationships theorized between an increase in the need to feel included in the group and to sustain positive self-conceptions with an increase in anxiety. While Gundykunst theorized an inverse relationship between increasing external confirmation of the positive self-conception and reduced anxiety, he also theorized a direct relationship between increasing dependence on the group for confirmation of self-esteem and anxiety. He also theorized a link between reduced uncertainty and reduced anxiety. Gundykunst suggested that increased attraction to strangers caused increased predictability that reduced uncertainty. Increased predictability, sense of security, and motivation to interact all cause a decrease in anxiety. The remaining axioms refer to increasingly attenuated relationships among various constructs and anxiety about intercultural communication. Novelty, familiarity, and the positive conception of self as self-confident are illustrated as precursors, although not necessarily causes of CA in Figure 1, which was developed by Aly and Gowing for purposes of analyzing their research results.

The characteristics of the individual speaker, however, develop in relationship with an ethnic context that differs in observable ways from the Anglo-U.S. ethnic context. The speaker's positive self-concept and self-confidence are entwined with ethnically derived and sustained rules about what constitutes an appropriate self (Ting-Toomey, 1993). Rules 
familiar to an audience from the individualist-oriented Anglo-U.S. context will differ fundamentally from rules familiar to speakers from more collectivist-oriented contexts such as Canada, Korea or Mexico in how they understand and express self-confidence. What is understood as appropriate, self-confident behavior in one context is both inappropriate and impolite in another (Kim, 1993). Indeed in some Asian ethnic contexts reticence rather than oral communication is highly valued as an indication of trustworthiness (Nakanishi \& Johnson, 1993). What constitutes communications competence in the Anglo-U.S. context does not do so in other ethnic contexts. One implication is that the greater is the speaker's unfamiliarity with what the audience considers appropriate, the higher will be the CA.

It is the speaker, however, who must discover the rules and then behave in ways that meet the expectations of the audience in order to be evaluated as appropriate and therefore competent (Cupach \& Imahori, 1993). Repeated success at exhibiting competence will diminish communications apprehension. In our study, the speaker is dependent on the Anglo-U.S. ethnic context of the audience for confirmation that behavior expressing the speaker's self confidence is appropriate. It is difficult to see how the speaker alone can either reverse or reduce this dependence. This dependence has important practical implications when considering how to identify and remedy communications anxiety. The streams of research on novelty, familiarity, and self-concept all imply that practice will reduce novelty, increase familiarity and improve the convergence of self-concept with the audience's expectations of appropriate behavior. The result will be an improvement in perceived communications competence, success, and a reduced feeling of communications apprehension.

Formality is another dimension of the situation that research in communications apprehension suggests is important. Intercultural research refers to the grammar of occasions that reflects the ritual or formality of situations (Nakanishi \& Johnson, 1993). In highly ritualized situations, the need for unique communication diminishes as a way to convey competence because predictable, appropriate phrases and gestures are both widely known and relatively easy to discover. The intercultural communication research highlights the differences in expectations that depend 
on ethnic context, while the communications competence research highlights the impact of these differences on the audience's evaluation of the speaker's competence. Portions of these strands of research also allude to causality among various factors and oral communications apprehension in different situations. In general the more novel the situation and unfamiliar the audience, the lower will be the speaker's self-confidence, and the higher will be communications apprehension. The ultimate result in intercultural communication is a performance that is perceived as lacking in either appropriateness, effectiveness, or both.

Work done by Milhouse (1993) in intercultural communication competence observed that people need both the will and the means (knowledge and skill) to become appropriate and effective intercultural communicators. Her research reaffirmed the relational nature of assessments of competence with effectiveness as the speaker's self-assessment, and appropriateness as the audience's assessment of the speaker. While she did not address how motivation or will, knowledge, and skill would reduce communications apprehension, her analysis did reveal that these three components are stable across cultures. All three are understood as important dimensions of a relational assessment of communications competence. The dimensions of the relationship between an audience and speaker with respect to the assessment of the speaker's competence are stable in a one-to-one situation. What varies is the specific behavior that the audience identifies as exhibiting knowledge and skill, for example interruptions are perceived as appropriate in one ethnic context but not another. In terms of remediation, Milhouse observed that improved motivation is probably dependent on the speaker's prior experience of success. Knowledge about the grammar of occasions, which can be interpreted as increased familiarity, would assist the speaker in influencing the audience's perception of appropriateness. Finally, as the specific skills of expressiveness, both gestures and vocal variety improve, so too will the perceived appropriateness of the speaker. Figure 1 derived by Aly and Gowing, from these converging streams of communications research to illustrate some recent ideas about how characteristics of both the situation and the person can affect the CA reported by different ethnic groups. 


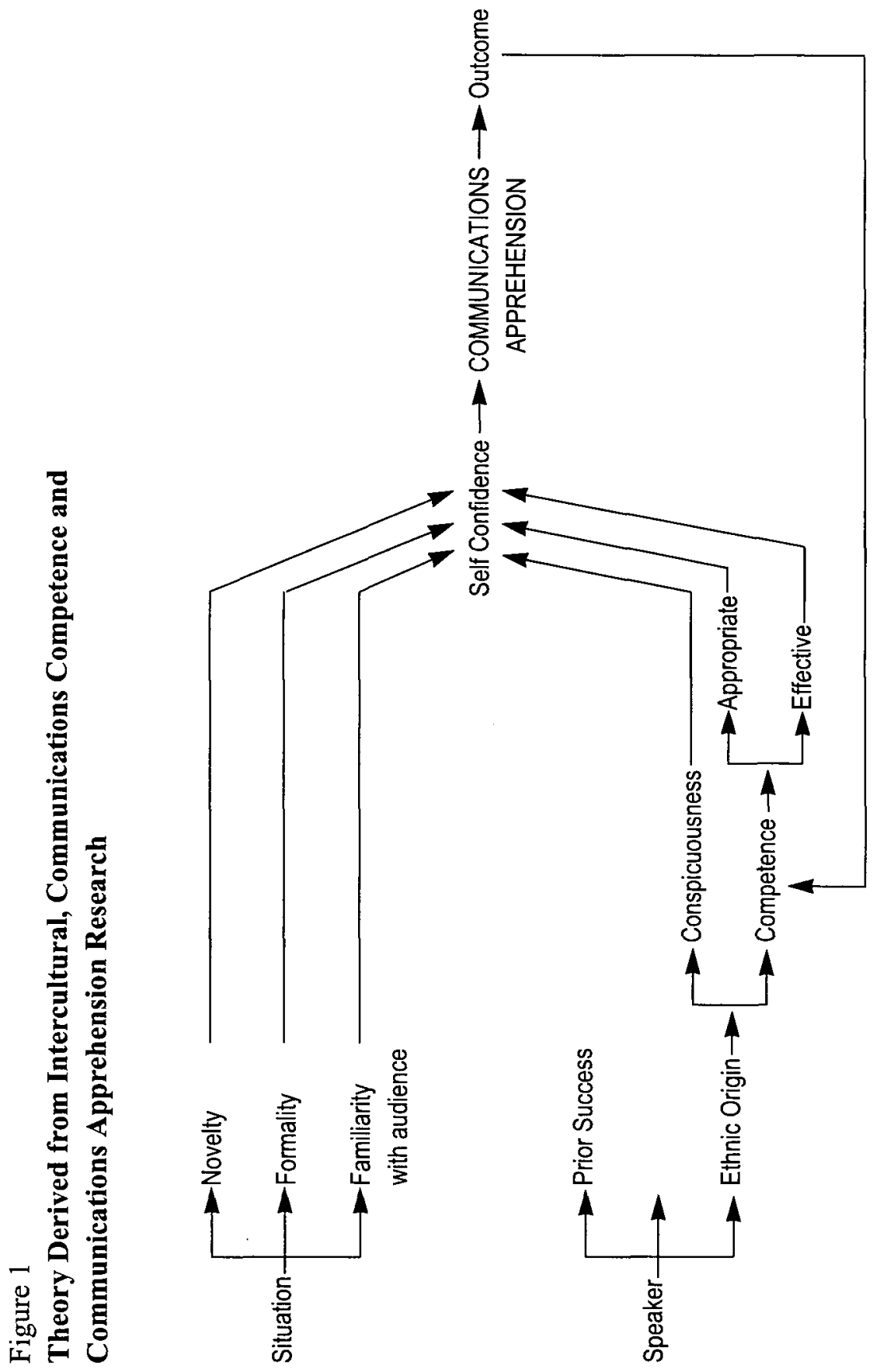

The Canadian Journal of Higher Education

Volume XXXI, No. 1, 2001 
Klopf (1984) completed a cross-cultural study of communications apprehension (CA) and ethnic origin among the cultures of the Pacific Basin (Australia, Japan, Korea, Micronesia, Peoples' Republic of China, and Philippines). Using the Personal Report of Communication Apprehension (PRCA) to compare levels of apprehension among cultural groups he compared the results from these different ethnic groups. Klopf was careful to note that one shortcoming of using an instrument developed in the United States to measure an affective construct like apprehension is the assumption that the target construct is both recognized and understood in the same way in all cultures. Nevertheless his exploratory study resulted in a suggestive ranking with students in Japan ranking highest in communications anxiety followed by those at the University of Hawaii, then the Peoples' Republic of China, Micronesia, Australia, Philippines, and Korea.

Our study adds to those in intercultural CA, a study of cross-cultural CA. What can be inferred from the theoretical development, however, is that the PRCA is not likely the best instrument to reveal whether the origin of apprehension is about the appropriateness or the effectiveness of the speaker. None of the PRCA questions directly address either issue. It is also important to note that in an educational setting such as a university accounting class, the instructor is most likely the only member of the audience who is formally evaluating the student's communications competence. This situation confounds somewhat because, in effect, the student may perceive the situation as a dyadic situation rather than a classroom situation. If the assessment of the entire audience is not germane to the mark the student achieves then a different measuring instrument may be more appropriate.

The PRCA questionnaire administered in this study is attached as Appendix 1. The questions ask students to report on the level of CA they believe they would feel in four different public speaking situations. The least public is the dyadic (questions $8,9,10,13,14$, and 18) and the situation to diagnose classroom presentations is the meeting (questions 1, 5, $7,19,22$, and 24). While the dyadic questions address the issue of familiarity (questions 8 and 14), there are no analogous questions in the meeting situation. The issue of familiarity with the participants in a 
conversation may also be confounded with that of the formality of the context. It is often in a more formal context (for example, a banquet) when we must converse with new acquaintances seated with us through random selection rather than by choice. Another dyadic situation, familiar to practicing accounting professionals, is the business lunch where there is a purpose to the conversation and profit may be at stake. The notion of what is to be risked or gained in the interchange in any communications setting is not addressed in the PRCA. For these reasons, the PRCA may be a reliable diagnostic tool to identify the presence of CA, however, it is not suitable to assess the reasons, either characteristics of the situation or those of the speaker. Without knowing the reasons for CA it is difficult to conclude how best to remedy CA. Perhaps an interpersonal skills measure such as the Conversational Skills Rating Scale (CSRS) used by Milhouse (1993) would better reflect the student's relative competencies and a basis for any appropriate remedial programs.

\section{METHOD}

The PRCA was administered at a large university to students enrolled in accounting courses. A total of 334 students completed the standard 24-item PRCA in which the order of the individual items had been randomised. Students were informed that the instrument consisted of 24 statements concerning their feelings about communication with other people. They were asked to indicate the degree to which each statement applied to them by marking whether they strongly agreed, agreed, were undecided, disagreed, or strongly disagreed with each statement. This sample comprised 173 men and 161 women. Of these 151 were first year students, 125 were final year, and 58 were in a graduate diploma program. First year students comprised $45.2 \%$ of the sample and final-year students $37.4 \%$ with $17.4 \%$ in the graduate diploma program. In the sample $63.8 \%$ of the students were full time, $41.9 \%$ of them had part-time employment, while $32.3 \%$ were not employed.

Because the law prohibits questions of ethnic origin, self-characterization as a native or non-native English-language speaker was used as a proxy for ethnic origin. Of the sample, 284 students characterized 
themselves as native English-language speakers while 50 described themselves as non-native English-language speakers. It should be noted that a problem arises from this method because the PRCA was devised to measure the CA of people from an Anglo-U.S. ethnic context. To use this instrument in diverse ethnic contexts is to assume both that CA exists in those contexts and that the PRCA is a valid and reliable way to measure CA. Moreover, the PRCA was administered in English and was not translated

\section{Statement Of Hypotheses}

The null hypotheses are:

1. $\mathrm{H}_{\mathrm{O}}$ : Communication Apprehension Score is not significantly different between native and non-native English speaking commerce students.

2. $\mathrm{H}_{\mathrm{O}}$ : Academic Achievement measured by GPA is not significantly different between native and non-native English speaking commerce students.

The overall PRCA score and the score for each of the four communication settings, public speaking, meeting, group and dyad, were computed for each student according to the model indicated by McCroskey (1984). McCroskey (1984) indicated that the nation-wide overall mean PRCA is 65.6 with standard deviation of 15.3. As a cut-off point for identifying students who clearly have high level of CA, McCroskey used scores that equal or exceed one standard deviation above the mean. Accordingly students whose overall PRCA score is 80.9 or higher have high CA and those at 50.3 or lower have low CA. McCroskey found that students with scores above one standard deviation from the mean had difficulty with public speaking.

Table 1 summarizes the results obtained from administering the PRCA to non-native English speaking and native English speaking commerce students. When compared to the national norms, our results indicate that the sample mean was 70.22 for non-native English speaking commerce student, higher than the national norm of 65.6. Furthermore, each mean in each setting was slightly higher for our sample compared to the national norm. The public speaking norm is 19.3 compared to our 
Table 1

\section{PRCA Students Results Between Native and Non-native English Speaking Commerce Students and National Norms}

\begin{tabular}{|c|c|c|c|c|c|c|}
\hline \multirow[b]{2}{*}{ PRCA } & \multicolumn{2}{|c|}{ National Norms } & \multicolumn{2}{|c|}{$\begin{array}{c}50 \text { Non-native } \\
\text { English speakers }\end{array}$} & \multicolumn{2}{|c|}{$\begin{array}{c}284 \text { Native } \\
\text { English speakers }\end{array}$} \\
\hline & $\tilde{\mathrm{N}}$ & S.D. & $\tilde{\mathrm{N}}$ & S.D. & $\tilde{\mathrm{N}}$ & S.D. \\
\hline Overall & 65.6 & 15.3 & 70.22 & 14.65 & 68.39 & 15.00 \\
\hline \multicolumn{7}{|l|}{ Public } \\
\hline Speaking & 19.3 & 5.1 & 20.06 & 4.19 & 19.27 & 4.47 \\
\hline Meeting & 16.4 & 4.8 & 17.70 & 4.46 & 17.76 & 4.79 \\
\hline Group & 15.4 & 4.8 & 16.76 & 4.01 & 16.24 & 4.35 \\
\hline Dyad & 14.5 & 4.2 & 15.70 & 5.11 & 15.12 & 4.58 \\
\hline
\end{tabular}

sample norm of 20.06 while the norm for meetings is 16.4 compared to our sample norm of 17.7. The group discussion norm is 15.4 compared to our sample norm of 16.76 and the dyadic norm is 14.5 compared to the sample norm of 15.7 .

The results also showed a slightly higher sample mean PRCA of 68.39 compared to the national norm and so too were the sample norms for each setting. The means for the native English speakers was also lower for each setting, with the exception of the meeting, than were the non-native English speakers. These results are suggestive but not conclusive and indicate a tendency for the Canadian sample as a whole to selfreport higher CA than do students in the U.S. studies.

The results of a one-way analysis of variance (ANOVA) to test whether or not the PRCA overall mean scores differ between the nonnative English-language speakers and native English-language speakers is shown in Table 2. At $\propto=0.05$, the analysis shows no significant difference between the means of the two groups and their overall self-reported level of CA.

Tables 3 to 6 provide detailed results of ANOVA, beginning with a comparison between the scores for non-native and native English speaking 
Table 2

Analysis of Variance Test of PRCA Overall Scores for Non-native English Speaking and Native English Speaking Commerce Students

\begin{tabular}{|l|c|c|c|c|c|c|c|}
\hline Group & $\begin{array}{c}\text { Number } \\
\text { of Cases }\end{array}$ & Mean & S.D. & $\begin{array}{c}\text { Stand. } \\
\text { Error }\end{array}$ & $\begin{array}{c}\text { Mean } \\
\text { SQ }\end{array}$ & F-Ratio & $\begin{array}{c}\text { F. } \\
\text { Prob. }\end{array}$ \\
\cline { 1 - 6 } Non-native & 50 & 70.22 & 14.64 & 2.07 & & & \\
\cline { 1 - 6 } Native & 284 & 68.39 & 15.00 & 0.89 & 141.70 & 0.6341 & 0.4264 \\
\hline
\end{tabular}

Table 3

Analysis of Variance Test of PRCA Public Speaking Scores for Non-native English Speaking and Native English Speaking Commerce Students

\begin{tabular}{|c|c|c|c|c|c|c|c|}
\hline Group & $\begin{array}{l}\text { Number } \\
\text { of Cases }\end{array}$ & Mean & S.D. & $\begin{array}{l}\text { Stand. } \\
\text { Error }\end{array}$ & $\begin{array}{c}\text { Mean } \\
\text { SQ }\end{array}$ & F-Ratio & $\begin{array}{c}\text { F. } \\
\text { Prob. }\end{array}$ \\
\hline Non-native & 50 & 20.06 & 4.19 & 0.59 & \multirow{2}{*}{26.46} & \multirow{2}{*}{1.3495} & \multirow{2}{*}{0.2462} \\
\hline Native & 284 & 19.27 & 4.47 & 0.27 & & & \\
\hline
\end{tabular}

Table 4

Analysis of Variance Test of PRCA Meeting Scores for Non-native English Speaking and Native English Speaking Commerce Students

\begin{tabular}{|l|c|c|c|c|c|c|c|}
\hline Group & $\begin{array}{c}\text { Number } \\
\text { of Cases }\end{array}$ & Mean & S.D. & $\begin{array}{c}\text { Stand. } \\
\text { Error }\end{array}$ & $\begin{array}{c}\text { Mean } \\
\text { SQ }\end{array}$ & F-Ratio & $\begin{array}{c}\text { F. } \\
\text { Prob. }\end{array}$ \\
\hline Non-native & 50 & 17.70 & 4.46 & 0.63 & & & \\
\cline { 1 - 6 } Native & 284 & 17.76 & 4.79 & 0.28 & 0.1559 & 0.0069 & 0.9336 \\
\hline
\end{tabular}


Table 5

Analysis of Variance Test of PRCA Group Scores for Non-native English Speaking and Native English Speaking Commerce Students

\begin{tabular}{|l|c|c|c|c|c|c|c|}
\hline Group & $\begin{array}{c}\text { Number } \\
\text { of Cases }\end{array}$ & Mean & S.D. & $\begin{array}{c}\text { Stand. } \\
\text { Error }\end{array}$ & $\begin{array}{c}\text { Mean } \\
\text { SQ }\end{array}$ & F-Ratio & $\begin{array}{c}\text { F. } \\
\text { Prob. }\end{array}$ \\
\hline Non-native & 50 & 16.76 & 4.01 & 0.57 & & & \\
\hline Native & 284 & 16.24 & 4.35 & 0.26 & 11.5210 & 0.6219 & 0.4309 \\
\hline
\end{tabular}

Table 6

Analysis of Variance Test of PRCA Dyad Scores for Non-native English Speaking and Native English Speaking Commerce Students

\begin{tabular}{|l|c|c|c|c|c|c|c|}
\hline Group & $\begin{array}{c}\text { Number } \\
\text { of Cases }\end{array}$ & Mean & S.D. & $\begin{array}{c}\text { Stand. } \\
\text { Error }\end{array}$ & $\begin{array}{c}\text { Mean } \\
\text { SQ }\end{array}$ & F-Ratio & $\begin{array}{c}\text { F. } \\
\text { Prob. }\end{array}$ \\
\hline Non-native & 50 & 15.70 & 5.11 & 0.72 & & & \\
\hline Native & 284 & 15.12 & 4.58 & 0.27 & 14.1427 & 0.6513 & 0.4202 \\
\hline
\end{tabular}

Table 7

T-Test of Students' Academic Achievement Between Native and Non-Native English Speaking Commerce Students

\begin{tabular}{|l|c|c|c|c|l|}
\hline Group & $\begin{array}{c}\text { Number } \\
\text { of Cases }\end{array}$ & Mean & S.D. & F- Value & Sig. \\
\hline Non-native & 50 & 2.896 & 0.426 & & \\
\cline { 1 - 4 } Native & 284 & 2.903 & 0.464 & & .475 \\
\hline
\end{tabular}


commerce students at the level of public speaking and, proceeding with the results of the PRCA for meeting, group, and dyad situations.

These analyses of the results of this study conclude with Table 7, a T-test of difference in grade point averages. Consistent with prior research, the group situation was considered analogous to the situation wherein a student is asked to do a presentation in the classroom.

A T-Test analysis was performed to test whether the Academic Achievement measured by GPA is differ between the non-native English speaking and native English speaking commerce students At $\propto=0.05$, the results in Table 7 indicated that the average GPA of non-native English speaking (2.896) was not significantly different from the average GPA of their native English speaking commerce students counterparts (2.903).

Taken as a whole, the results shown in Tables 1 through 7 suggest that the level of communications apprehension reported by both nonnative and native English speakers is not significantly different, nor is their actual academic achievement. These results did not change with the level of education students had currently achieved and imply that ethnic origin is not a determinant of either CA or competence.

\section{DISCUSSION}

The results of this study imply that proxies of ethnic origin are neither correlated with levels of communications anxiety, nor academic accomplishment. Prior research has identified relationships, both direct and inverse, between the level of CA and other variables. The study was motivated by the assumption that students of other than Anglo-U.S. ethnic origin would have less familiarity with a predominantly Anglo-U.S. audience and therefore would not only report higher levels of CA but would also demonstrate concomitant lower levels of accomplishment. It was also assumed that the Canadian sample was homogeneous with samples used in U.S. research. That such differences were not supported by the results of this study may be attributed in part to the diversity inherent in both the student and teacher populations at the university where the study took place. At the university, an explicit and conscientious effort 
has been made over the last several years to ensure the diversity not only of the student but also of the teacher populations. Therefore, the student's audience may not be predominantly of Anglo-U.S. origin. Moreover, students and their instructors alike may have had considerable prior experience in both formal and informal crosscultural communication. During the course of prior experience both groups have had the opportunity to converge on a range of behaviors that will convey competence. The result may be a broader scope of appropriate behavior and less rigid set of criteria whereby the student's competence is assessed by the audience. The student may also have been in the Anglo-U.S. milieu long enough to feel familiar with the means to exhibit the appropriate levels of self-esteem, assertiveness, expressiveness, friendliness, and politeness that will communicate competence congruent with AngloU.S. expectations. That is, students have obtained not only the knowledge that they must convey self confidence and competence, but also the skill required to select specific gestures and expressions to do so.

The students who present their work in the classroom may perceive themselves as neither alien to, nor unfamiliar with their audience's expectations. In specific situations it may be the case that both student and teacher are from the same ethnically diverse non-native Englishlanguage population thereby reducing the unfamiliarity of the expectations between the student and one key member of the audience who has formal responsibility for assessing competence. Alternatively, the student may be presenting to a class comprised of several others from the student's own ethnic background, thereby increasing the student's familiarity with some proportion of the cultural context and reducing the gap between the speaker's self-concept and the audience's expectations of appropriate behavior. The presence of others from the student's own ethnic background would also reduce the student's conspicuousness, and dependence on being accepted by an audience comprised of strangers. Aside from the issue of convergence of self-concept with the audience's expectations, the student need not be self confident but must be perceived by the audience as self confident. To do so, the students in this sample may have discovered the rules and received confirmation from their peers and instructors that they exhibit specific behaviors that 
express self confidence. Knowing how to express self confidence not only enhances the audience's perception of the speaker's competence but also reduces the speaker's communications anxiety.

It may be concluded that proxies of ethnic origin (native or non-native English language speech) pose no systematic barriers to either obtaining higher education or educational accomplishment for this sample of commerce program students. This conclusion is supported by the lack of difference in levels of communications apprehension among students in their preliminary and terminal years. Before accepting this conclusion, however, further research is required. The study did not examine only those students who declared accounting as their major because an initial analysis revealed no differences in levels of CA based on declared major.

A more rigorous approach would be to survey all accounting students throughout their academic careers, and to use two self-reporting instruments, one to measure communications apprehension, and one to measure communications competence. By using two measures, the relationship between communications apprehension perceived by the speaker, and communications competence perceived by the audience could be assessed. Assuming that as students progress to higher level courses the demand for presentations increases, so too should their familiarity with the grammar of such occasions. Because the accounting students must all take the same courses, they form cohorts and become familiar with each other and their instructors. This approach would permit a study of how novelty and familiarity affect both apprehension and competence. Thus a longitudinal study would permit an analysis of results from year to year for the same cohort of students to determine if there is a significant decline in communications apprehension and increase in communications competence based on situational characteristics.

The use of two instruments would allow an investigation of the extent to which the students' self-perception of apprehension converge or diverge from the audience's evaluation of their competence. In addition such a study would permit an assessment of which measure most closely correlates to measures of achievement such as Grade Point Average (GPA) in the accounting courses where presentations are required and contribute a substantial amount to the overall mark in the 
course for the student. Before concluding that ethnic origin may be a source of systematic bias against some accounting students, further investigation is required to more clearly assess what the sources of problems are in either apprehension or competence.

The structure of the commerce program has a substantial requirement for not only communication among teams of students, but also for individual classroom presentations. While the lecture format remains the workhorse for many introductory courses, most instructors assess the student's participation in class in some way that measures their oral communications competence. This activity is not, however, a formal presentation, and the contribution towards the student's final mark in a course is typically $10 \%$ to $15 \%$. In part, this dynamic may explain why there is no significant difference in the GPA attributable to ethnic origin. The proportion of each mark comprising the GPA that depends upon oral communication is relatively low. Nevertheless, it would be useful to assess the extent to which ethnic origin influences the student's opportunity to maximize this portion of their final mark.

The notion that classroom presentations are more dyadic for students because their evaluation rests on only one other audience member is the reason for suggesting further research using a second instrument such as the Conversational Skills Rating Scale (CSRS). In this way, not only communications apprehension, but also communications competence can be measured. In measuring competence, various stable dimensions have already been identified. If it is important to improve the competence of students who have diverse ethnic origins, then the CSRS may be a better diagnostic tool than the PRCA. The skills required to convey competence in the form of appropriateness are well identified in the CSRS and therefore have practical use in designing any remedial program if one is necessary. Nevertheless, the PRCA would reveal if the remedial program also reduces communications apprehension.

An emphasis on dyadic communication also coincides with the results of studies that show how important success in one-on-one client communications is to accountants. In other words, students can not only improve the contribution that oral communication makes while in university, but also their ability to obtain an employment interview and 
enjoy a successful career in an Anglo-U.S. context. The barriers to implementing this approach, however, rest not simply on the limited data available from this study. There are tangible resource constraints facing every university and even if a suitable and effective remedial program could be designed to identify and assist students to improve communications competence, other educational priorities may be more urgent. Moreover, if it is the instructor whose assessment of the student is most important it may be that remedial work should be directed at instructors to sensitize them to the ways that non-Anglo-U.S. ethnic groups demonstrate competence.

The reduction of communications apprehension through increased practice at presentations in class may not coincide with pedagogical objectives. It is not safe to assume either that as the level of courses progresses so too does the level of pedagogical objective, or that instructors have a sophisticated awareness of pedagogical theory. Where the pedagogical objectives of higher level courses emphasize the acquisition of vocabulary, identification and classification of transactions, or the application of accounting principles and methods, presentations are an inappropriate means to achieve these learning goals (Bonner, 1999). It is only when the production and application of higher order judgment rules and cognitive strategies are the pedagogical goals that presentations are one but not the only appropriate means to achieve these goals. Hence, a refined study of both communications apprehension and competence might better focus on those accounting courses where higher order acquisition of cognitive skills is the primary pedagogical goal. This focus may not comprise a substantial proportion of accounting courses and, therefore, may not provide sufficient opportunity for students to acquire the familiarity needed with public presentations to either reduce their apprehension or improve their competence.

It may well be, however, that the students entering a university commerce program have already self-selected into the program and this is why there is no significant difference in either their CA or their communications competence as reflected in their GPA. Clarification could be obtained through a comparative study of student cohorts in science, engineering, and the arts. Irrespective of their ethnic origins, students 
have already developed a satisfactory history of prior success in dyadic communication that can be transferred into the classroom situation where the instructor is the dominant evaluator of competence. Finally, the use of non-native and native English speakers as a proxy for diverse ethnic origin may be an incorrect proxy. A refinement could be to classify the non-English languages into language families to determine, for example, if significant differences exist because the language of origin is Slavic rather than Latin. These particular study results may have targeted young immigrants with extensive prior successful experience in various levels of public oral communications because they have already achieved English-language competence. That is, the ethnic origin may be unrelated to both experience and competence in dealing with a predominantly Anglo-U.S. audience for relatively young immigrants who may speak a language other than English only in the home.

\section{CONCLUSION}

The results of this study do not support the notion that this type of proxy for ethnic origin affects the level of communications apprehension or the academic achievement of students in a commerce program. The results of this study are anomalous. Further studies should establish what systematic differences in CA, if any, exist between the U.S. and Canadian student, irrespective of the ethnic origins of these students. There is also an opportunity to investigate not only reported CA but also an independent measure of competence using a different survey instrument. The theoretical implications are that a more sophisticated assessment is required not simply to diagnose the presence of communications apprehension but also to reveal the source of the apprehension. Without knowing how the apprehension arises, it is difficult to foresee how to create an appropriate remedy. To improve the competitiveness of students in the accounting job market and to enhance their possibilities of career success, this research should be pursued to produce not merely diagnoses but rather prescriptions. In a practical sense, the allocation of scarce university resources to remedy communications apprehension may be premature. More important, it may also be a misallocation if the 
goal of reduced apprehension is in conflict with pedagogical goals. The conclusion that there exists a relationship between decreased communications apprehension and increased professional communication skills to assure higher academic achievement, professional placement, and career success may have been premature.

\section{References}

Akerlof, G. (1970). The market for lemons. Quarterly Journal of Economics, August, 488-500.

Blatzer, D. (1997). Communications apprehension. Third Annual Student Research Conference Proceedings, May 29, 1997.

Bonner, S.E. (1999) Choosing teaching methods based on learning objectives: An integrative framework. Issues in Accounting Education, 13-19.

Cupach, W.R., \& Imahori, T.T. (1993). Identity management theory: Communication competencce in intercultural episodes and relationships. In R.L. Wiseman \& J. Koester (Eds.) Intercultural communication competence (pp. 112-131). Newbury Park, CA: Sage Publications Inc.

Daly, J.A., \& McCroskey, J.C. (1974). Occupational desirability and choice as a function of communications apprehension. Journal of Counselling Psychology, 22, 309-313.

Friedrich, G.,\& Gross, B. (1984). Systematic desensitization. In J.A. Daly \& J.C. McCroskey (Eds.), Avoiding communication: Shyness, reticence, and communication apprehension, 2nd edition (pp. 173-187). Beverly Hills, CA: Sage Publications Inc.

Gundykunst, W.B. (1993). Toward a theory of effective interpersonal and intergroup communication: An anxiety/uncertainty management (AUM) perspective. In R.L. Wiseman \& J. Koester (Eds.) Intercultural communication competence (pp. 33-71). Newbury Park, CA: Sage Publications Inc.

Kim, M.-S. (1993). Culture-based interactive constraints in explaining intercultural strategic competence. In R.L. Wiseman \& J. Koester (Eds.) Intercultural communication competence (pp. 132-150). Newbury Park, CA: Sage Publications Inc.

Klopf, D.W. (1984). Cross-cultural apprehension research: A summary of pacific basin studies. In J.A. Daly \& J.C. McCroskey (Eds.), Avoiding communication: Shyness, reticence, and communication apprehension, 2nd edition (pp. 157-169). Beverly Hills, CA: Sage Publications Inc. 
Klopf, D., \& Cambra, R. (1979). Communication apprehension among college students in America, Australia, Japan and Korea. Journal of Psychology, 102, 27-31.

Koester J., Wiseman, R.L., \& Sanders J.A. (1993), Multiple perspectives of intercultural communication competence. In R.L. Wiseman \& J. Koester (Eds.) Intercultural communication competence (pp. 3-15). Newbury Park, CA: Sage Publications Inc.

Krzystofik A.T., \& Fein, R. (1998). Does your firm use the right approach in hiring campus recruits? Journal of Accountancy, November, 83-88.

Martin, J. (1993). Intercultural communication competence: A review. In R.L. Wiseman \& J. Koester (Eds.) Intercultural communication competence (pp. 16-29). Newbury Park, CA: Sage Publications Inc.

McCroskey, J.C. (1977). Classroom consequences of communication apprehension. Communication Education, 26, 27-33.

McCroskey, J.C. (1978). Validity of the PRCA as an index of oral communication apprehension. Communication Monographs, 45, 192-203.

McCroskey, J.C. (1982). Communication competence and performance: A research and pedagogical perspective. Communication Education, 3I(1), 1-7.

McCroskey, J.C. (1984). The communication apprehension perspective. In J.A. Daly \& J.C. McCroskey (Eds.), Avoiding communication: Shyness, reticence, and communication apprehension (pp. 13-38). Beverly Hills, CA: Sage Publications Inc.

McCroskey, J.C., \& Andersen, J.F. (1976). The relationship between communication apprehension and academic achievement among college students. Human Communication Research, 3(1), 73-81.

McCroskey, J.C., Booth-Butterfield, S., \& Payne, S.K. (1989). The impact of communication apprehension on college student retention and success. Communication Quarterly, 37(2), 100-107.

McThomas, D.W., \& Hanson, G.A. (1987). Management of an accounting practice. CPA The Journal, December, 118-122.

Milhouse, V.H. (1993). The applicability of interpersonal communication competence to the intercultural communication context. In R.L. Wiseman \& J. Koester (Eds.) Intercultural communication competence (pp. 184-203). Newbury Park, CA: Sage Publications Inc. 
Nakanishi, M., \& Johnson, K.M. (1993). Implications of self-disclosure on conversational logics, perceived communication competence, and social attraction: A comparison of Japanese and Americal cultures. In R.L. Wiseman \& J. Koester (Eds.) Intercultural communication competence (pp. 204-221). Newbury Park, CA: Sage Publications Inc.

Richmond, V. (1984). Implications of quietness: Some facts and speculations. In J.A. Daly \& J.C. McCroskey (Eds.), Avoiding communication: Shyness, reticence, and communication apprehension (pp. 145-155). Beverly Hills, CA: Sage Publications Inc. .

Scott, M.D., McCroskey, J.C., \& Sheahan, M.E. (1978) Measuring communication apprehension in the organization setting. The Journal of Communication, 28, 104-111.

Stanga K.G., \& Ladd, R.T. (1990). Oral communication apprehension in beginning accounting majors: An exploratory study. Issues in Accounting Education, 5(2), 180-184.

Ting-Toomey, S. (1993). Communicative resourcefulness: An identity negotiation perspective. In R.L. Wiseman \& J. Koester (Eds.) Intercultural communication competence (pp. 72-111). Newbury Park, CA: Sage Publications. 


\section{Appendix}

\section{Dear Participant}

You are cordially invited to participate in a research project involving oral communications. Your participation in this study is greatly appreciated. Your responses will be treated completely anonymously and the way you respond to the questions in this instrument has no bearing on your performance in this course. Your answers will only be used for research purposes. This instrument is composed of 24 statements concerning your feelings about communication with other people. Please indicate in the space provided the degree to which each statement applies to you by marking whether you:

\section{Strongly Agree \\ 2. Agree \\ 3. Neutral \\ 4. Disagree \\ 5. Strongly Disagree}

with each statement. There are no right or wrong answers. Many of the statements are similar to other statements. Do not be concerned about this. Work quickly; just record your first impression.

1. Generally, I am nervous when I have to participate in a meeting.

2. I feel relaxed while giving a speech.

3. I like to get involved in group discussion.

4. I dislike participating in group discussion.

5. I am afraid to express myself at meetings.

6. I have no fear of giving a speech.

7. Communicating at meetings usually makes me uncomfortable.

8. While participating in a conversation with a new acquaintance, I feel very nervous.

9. I have no fear of speaking up in conversations.

10. Ordinarily I am very tense and nervous in conversations.

11. Generally, I am comfortable while participating in a group discussion.

12. I face the prospect of giving a speech with confidence.

13. Ordinarily I am very calm and relaxed in conversations.

14. While conversing with a new acquaintance, I feel very relaxed.

15. Engaging in group discussion with new people makes me tense and nervous.

16. I am calm and relaxed while participating in group discussion.

17. My thoughts become confused and jumbled when I am giving a speech.

18. I am afraid to speak up in conversations. 
19. I am very calm and relaxed when I am called upon to express an opinion at a meeting.

20. Certain parts of my body feel very tense and rigid while giving a speech.

21. While giving a speech I get so nervous, I forget the facts I really know.

22 I am very relaxed when answering questions at a meeting.

23. I am tense and nervous while participating in group discussion.

24. Usually, I am calm and relaxed while participating in meetings.

1. Your age ___ years

2. What language do you know other than English? French Other (specify)

3. Gender: Male Female

4. Your Major: Student Status Full Time Part Time

5. Your Overall Grade-Point Average:

6. Do you have a full time job? Or a part time job No job

7. Number of years of work experience years 